\title{
Kinetic and Thermodynamic Study of the Dephosphation of Wastewater by Clay Materials from Côte d'Ivoire
}

\author{
Ake Ake Pierre ${ }^{1}$, Kedi Atolé Brice ${ }^{2}$, Coulibaly Vamoussa1, \\ Kouame N'Dri' ${ }^{1}$, Sei Joseph ${ }^{1}$, Et Oyetola Samuel ${ }^{1}$
}

${ }^{1}$ Laboratoire de Constitution et Réaction de la Matière, UFR SSMT, Université Félix Houphouët-Boigny, Abidjan, Côte d'Ivoire

${ }^{2}$ Laboratoire des Sciences et Technologies de l'environnement, UFR Environnement, Université Jean Lorougnon Guédé,

Daloa, Côte d'Ivoire

Email: *meake@yahoo.fr

How to cite this paper: Pierre, A.A., Brice, K.A., Vamoussa, C., N'Dri, K., Joseph, S. and Samuel, E.O. (2021) Kinetic and Thermodynamic Study of the Dephosphation of Wastewater by Clay Materials from Côte d'Ivoire. Open Journal of Applied Sciences, 11, 1307-1323.

https://doi.org/10.4236/ojapps.2021.1112099

Received: November 5, 2021

Accepted: December 27, 2021

Published: December 30, 2021

Copyright $\odot 2021$ by author(s) and Scientific Research Publishing Inc. This work is licensed under the Creative Commons Attribution International License (CC BY 4.0).

http://creativecommons.org/licenses/by/4.0/

\begin{abstract}
Phosphorus is introduced into the aquatic environment from different point sources, mainly by domestic and industrial wastewater; contributing to the eutrophication of water bodies. The most common way for wastewater dephosphation is the injection of expensive chemicals into these bodies of water. Thus, the main objective of this work was to find an alternative to chemicals by using clay materials from Côte d'Ivoire to adsorb phosphate ions from aqueous solutions. The clay samples, taken from various regions were characterized by X-ray diffraction. They have a different mineralogical composition. The influence of various parameters such as the $\mathrm{pH}$ of the medium, contact time, the ion force, temperature, etc. on the adsorption was studied. Adsorption is influenced by the temperature, the $\mathrm{pH}$ of the medium, valence of the saturated cation and the clay composition. It is described by a kinetic model of the pseudo-second order. The salt of the medium has no significant effect on the process. The thermodynamic study revealed that adsorption is spontaneous, endothermic and that it is done by electrostatic means of physical nature.
\end{abstract}

\section{Keywords}

Adsorption, Clay, Phosphate, Eutrophication, Wastewater, Kinetic, Isotherm

\section{Introduction}

Water is a vital resource that man uses for his needs. Its good quality allows us to eat, practice sports, fishing, tourism in order to have a good physical, moral, fi- 
nancial health, etc., but the various anthropic activities exercised by man on the natural environment considerably degrade the quality of the environment and water resources. Indeed, the demographic growth of urban cities, the establishment of industrial areas near waterways, the use of chemical fertilizers, the development of livestock have considerably increased the production of wastewater that is often enriched in organic matter and nutrients (phosphorus and nitrogen, in particular) necessary for plant growth. These waters, when discharged into nature without adequate treatment, cause an imbalance in aquatic ecosystems and eutrophication of lakes, rivers, streams and watercourses with low hydrodynamics [1] [2] [3] [4].

In fact, eutrophication is characterized by the anarchic appearance of aquatic plants (algae, macrophytes...) [5] and plankton when a bodie of water contains a high concentration of phosphate and nitrogen. These invasive aquatic plants considerably reduce the quantity of drinking water, prevent the practice of sports, tourism activities, fishing (industrial or artisanal), the production of drinking water [3] [5] [6], which has very significant repercussions on the human and socio-economic health of a municipality or a region. Today, eutrophication is a major environmental problem.

To solve this problem of eutrophication, manual and mechanical removal, the application of herbicides, biological attack and the use of financial and material resources are commonly used, but it turns out that these processes are not very effective and that aquatic plants reappear immediately. In addition, several studies have proposed preventive and curative methods to fight against eutrophication [2] [7] [8]. These studies point out that phosphorus is the limiting factor [1] [9] [10] [11] on which action must be taken to reduce the proliferation of aquatic plants, and consequently the limitation of the eutrophication phenomenon. The dephosphatation of wastewater is undoubtedly a means of controlling eutrophication. It can be done by physicochemical processes based on precipitation reactions with iron, aluminum or calcium based reagents, biological processes with bacteria and adsorption which has many advantages, and can be done with several types of materials including biomaterials.

In a policy of environmental protection, biomaterials, natural, abundant, inexpensive and with great capacities of phosphate adsorption, are increasingly used [12] [13] [14]. It is appropriate to complement these studies by valorizing other biomaterials as phosphate adsorbents. It is within this framework that our study is included, with the ambition to participate in an environmental protection policy to use clay materials from Côte d'Ivoire for wastewater dephosphation.

To achieve this goal, after having collected clay samples in various regions of Ivory Coast, we will determine their mineralogical characteristics, then study the influence of various parameters such as the contact time, the $\mathrm{pH}$ of the medium, the temperature, the ionic strength and the quantity of clay on the adsorption, finally to identify the mechanisms of adsorption brought into play and to make a comparative study of the effectiveness of the adsorbents. 


\section{Materials and Methods}

\subsection{Clay Samples}

The study is carried out on three different clays of the soils of Ivory Coast. These are a sample from Korhogo noted KOR, a sample from Katiola noted KAT and a sample from Anyama noted ANY. These samples were previously characterized by X-ray diffraction using a BRUKER D8 ADVANCE apparatus operating at the wavelength $\lambda=1.7903 \AA$ of cobalt.

The clay samples taken from the soil, are dried in the shade for several days, then they are crushed in an agate mortar. The resulting powder is sieved to 100 $\mu \mathrm{m}$. Then, these well-crushed and sieved samples, underwent sedimentation to collect the clay fraction with diameter $<2 \mu \mathrm{m}$. Then, the collected clay fractions, were treated with saturating cations $\left(\mathrm{Mg}^{2+}\right.$ and/or $\left.\mathrm{Na}^{+}\right)$. This treatment resulted in 6 clay solutions at $10 \mathrm{~g} \cdot \mathrm{l}^{-1}$, designated ANY-Na; ANY-Mg; KAT-Na; KAT-Mg; KOR-Na and KOR-Mg that served as adsorbents.

\subsection{Adsorption Procedure}

The solution used as the phosphate source was obtained by dissolving potassium hydrogen phosphate $\mathrm{KH}_{2} \mathrm{PO}_{4}$ in distilled water.

The adsorption experiments were performed in Batch system, checking the influence of parameters such as clay mass, $\mathrm{pH}$ of the medium, contact time, ionic strength, temperature and initial phosphate concentration on the adsorption phenomenon. The tests were performed by mixing a certain volume of $10 \mathrm{~g} \cdot \mathrm{l}^{-1}$ clay solution with a volume of phosphate solution containing salt $(\mathrm{NaCl}$ or $\mathrm{MgCl}_{2}$ ), so as to have a mixture of volume $10 \mathrm{~mL}$ and $5 \mathrm{mg} \cdot \mathrm{l}^{-1}$ of phosphate. The resulting mixtures were then kept under stirring at $480 \mathrm{rpm}$ using a VIBRAMAX 100 type mechanical stirrer for 120 minutes (previously determined reaction time) at the temperature of $303 \mathrm{~K}$, then the supernatants taken after centrifugation at $5000 \mathrm{rpm}$ for a period of 30 minutes using a centrifuge type UNIVERSAL 320R, were analyzed with a UV-Visible spectrophotometer at the wavelength $880 \mathrm{~nm}$ using an apparatus type SHIMADZU UV 1700. To each supernatant was added $1 \mathrm{~mL}$ of a mixture consisting of ammonium molybdate, potassium antimony double tartrate, concentrated sulfuric acid, ascorbic acid and water, 15 minutes before the spectrophotometer analysis. The residual phosphate concentration was determined using a calibration curve made from a range of known phosphate concentrations.

The tests relating to the influence of the contact time, were carried out by varying the contact time from 0 to 5 hours. For the influence of the mass, the efficiency of phosphate removal was studied by varying the clay mass from 5 to 50 $\mathrm{mg}$. To check the influence of $\mathrm{pH}$, the tests were performed by varying the $\mathrm{pH}$ from 2 to 10 with a decimolar solution of $\mathrm{HCl}$ or $\mathrm{NaOH}$. For the temperature, the values $293 \mathrm{~K}\left(20^{\circ} \mathrm{C}\right), 303 \mathrm{~K}\left(30^{\circ} \mathrm{C}\right), 313 \mathrm{~K}\left(40^{\circ} \mathrm{C}\right)$ and $323 \mathrm{~K}\left(50^{\circ} \mathrm{C}\right)$ were chosen. To better understand the influence of $\mathrm{Na}^{+}$and/or $\mathrm{Mg}^{2+}$ ions on the adsorption process, the tests were performed by varying (from 0 to $0.1 \mathrm{~mol} \cdot \mathrm{l}^{-1}$ ) the salt concentration $\left(\mathrm{NaCl}\right.$ or $\left.\mathrm{MgCl}_{2}\right)$ of the clay-phosphate solution mixtures. 


\section{Results}

\subsection{Characterization of the Clay Samples}

\subsubsection{Mineralogical Analysis}

The X-ray diffraction spectra obtained are presented in Figures 1-4:

- The diffractograms in Figure 1 and Figure 2 reveal that the ANY sample contains chlorite (lines at $14.09 \AA$; $7.06 \AA$; $4.71 \AA$; $3.53 \AA$; and $2.82 \AA$ ), illite (lines at $9.94 \AA ; 4.98 \AA$; and $1.99 \AA$ ), and smectites (lines at $14.83 \AA$ (Figure 2(a)) and lines at $17.04 \AA$ and $8.49 \AA$ (Figure 2(b))). Associated with these minerals are quartz (lines at $4.25 \AA$; $3.34 \AA$; $2.28 \AA ; 2.13 \AA$ and $1.82 \AA$ ) and rutile (lines at $3.2 \AA$ and $2.46 \AA$ ).

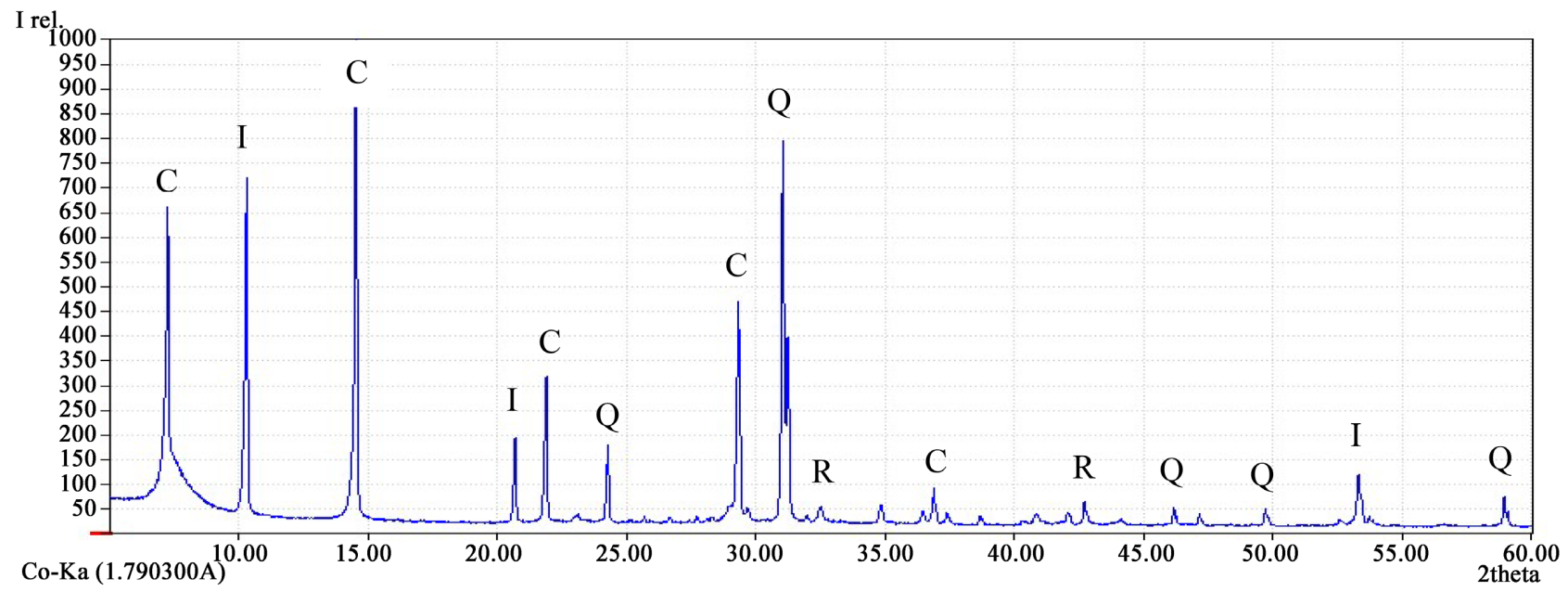

Figure 1. X-ray diffractogram of the total rock of the ANY sample.

I rel.

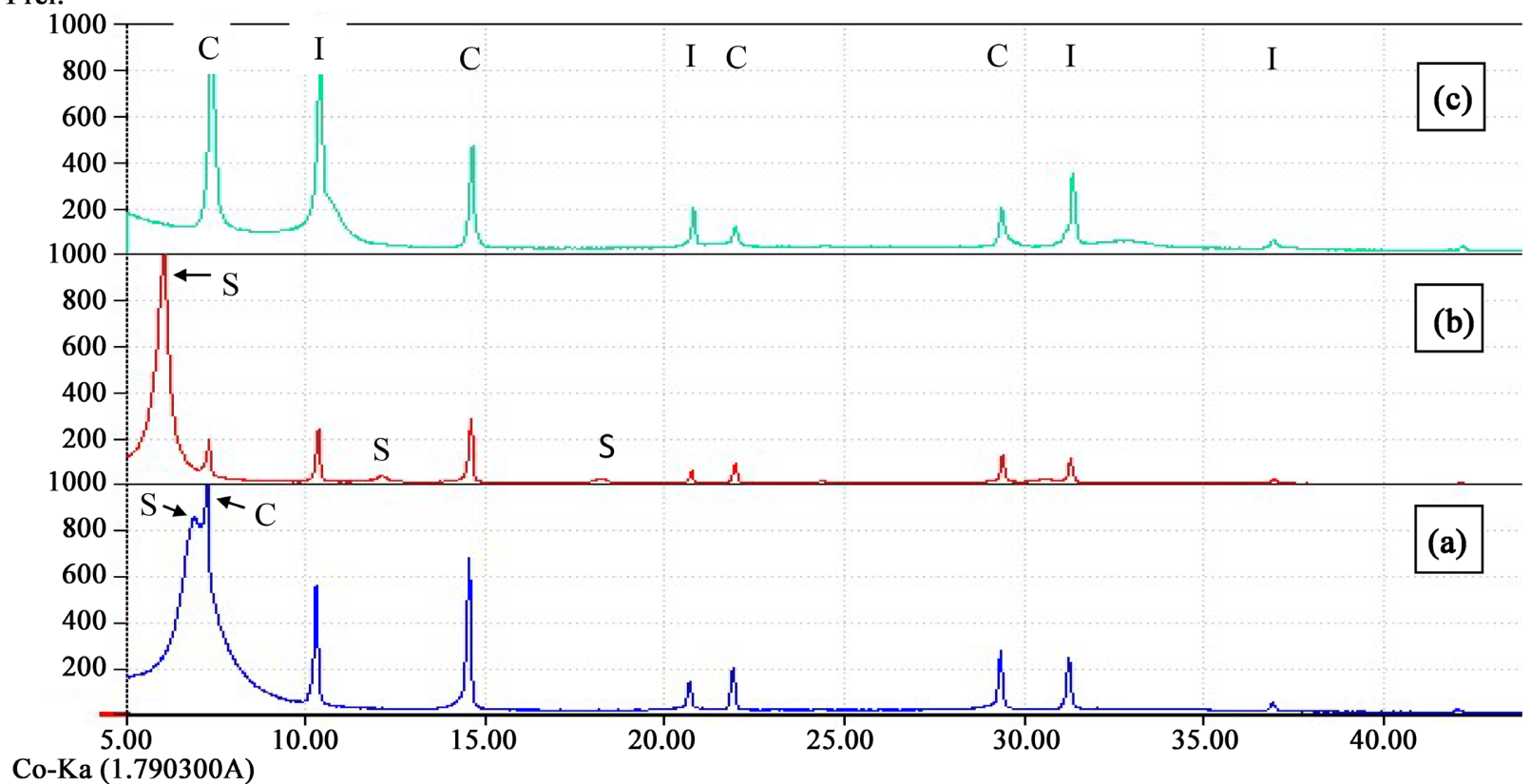

Figure 2. X-ray diffractograms of the fine fraction of the ANY sample. (a) Normal slide; (b) sample treated with ethylene glycol; (c) sample treated at $773 \mathrm{~K}$. 
- The diffractograms in Figure 3 and Figure 4 show that the KAT and KOR samples consist of kaolinite (lines at 7.15 - $7.17 \AA$; $4.46 \AA$ and $3.57 \AA$ ), illite (lines at $9.94 \AA$; $4.98 \AA$ and $1.99 \AA$ ), quartz (lines at $4.25 \AA$; $3.34 \AA$; $2.28 \AA$; $2.13 \AA$ and $1.82 \AA$ ) and rutile (line at $3.24 \AA$ and $2.46 \AA$ ). In addition to these minerals, sample KAT also contains smectites (lines at $14.17 \AA$ and $4.03 \AA$ ) and sample KOR, goethite (lines at $4.15 \AA$ and $2.56 \AA$ ).

\subsubsection{Mineralogical Composition}

The theoretical results of the mineralogical composition of the clay samples are given in Table 1.

The results show that sample ANY is richer in quartz (25.69\%), illite (21.44\%) and chlorite (23.54\%) than the other two samples, however it contains the lowest content of smectite $(12.50 \%)$. The highest smectite content $(20.90 \%)$ is contained in sample KAT. As for sample KOR, it is relatively rich in goethite (9.14\%), kaolinite (49.71\%) and rutile (1.52\%), however it is less rich in illite $(2.80 \%)$. The presence of goethite could make the KOR sample particularly adsorbent.

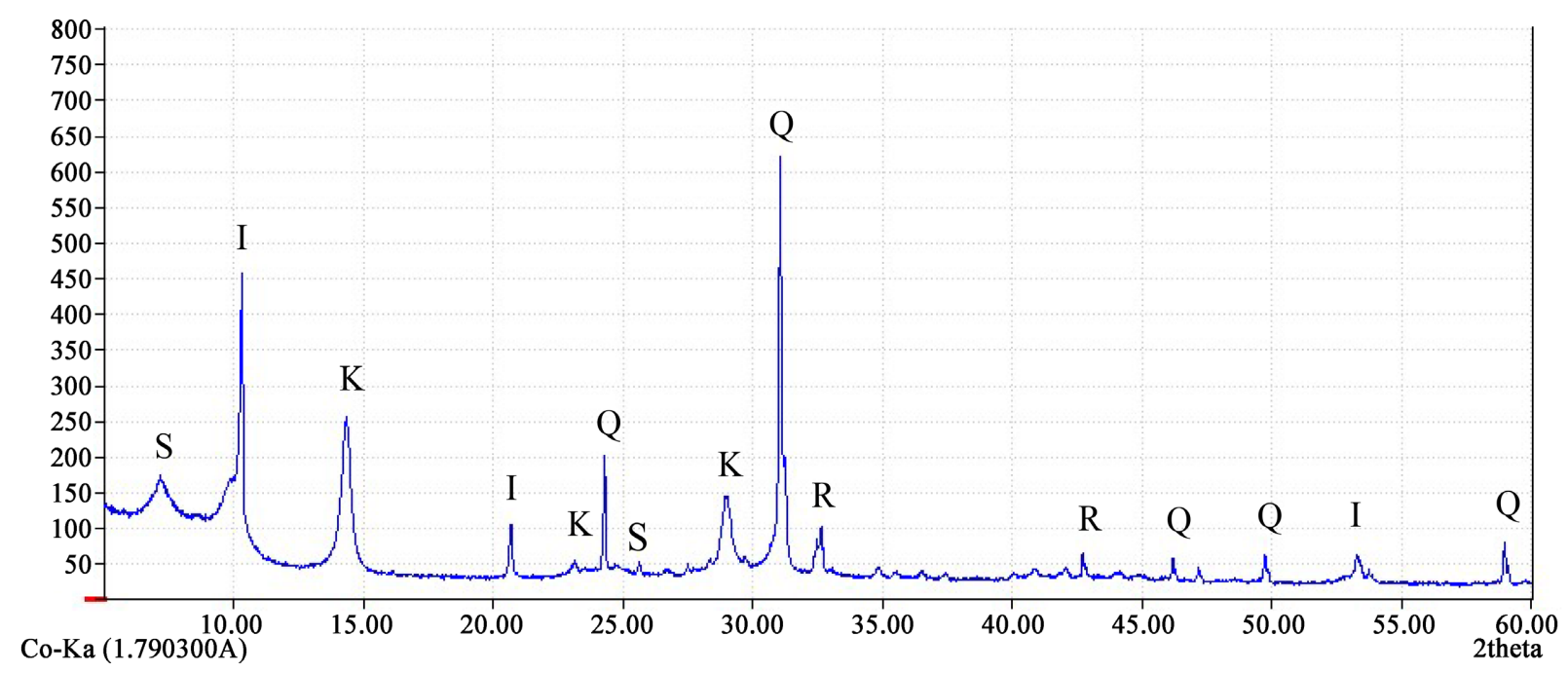

Figure 3. X-ray diffractogram of the total rock of the KAT sample.

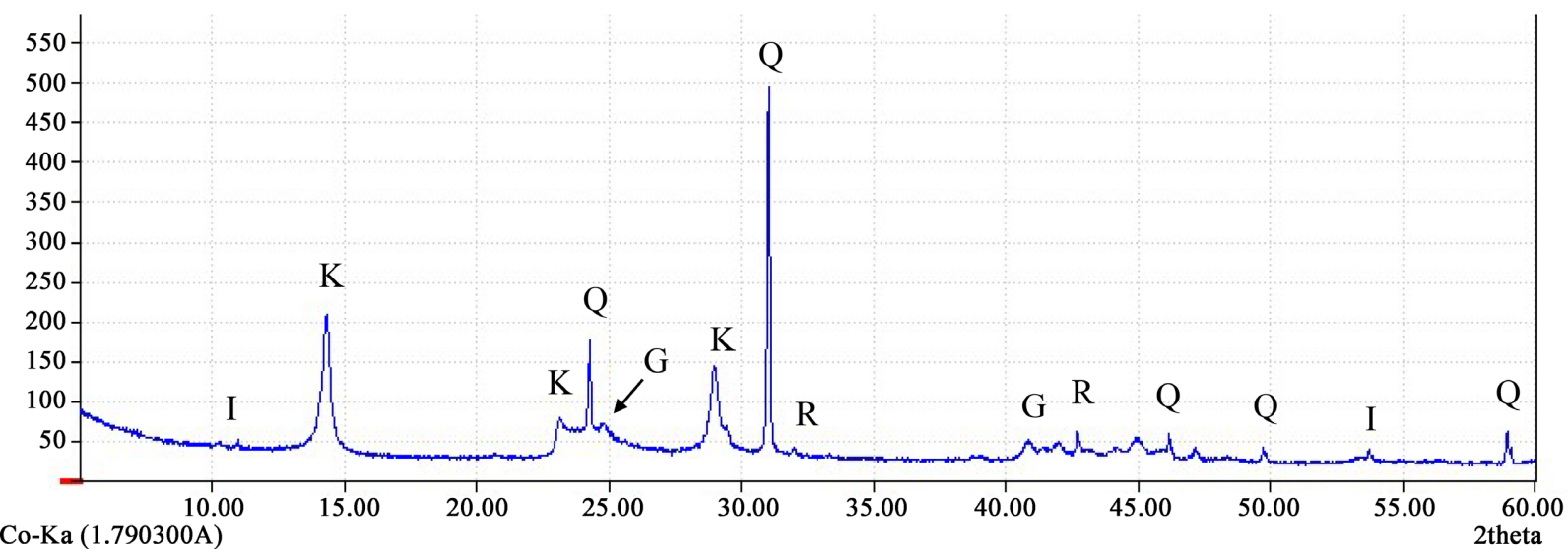

Figure 4. X-ray diffractogram of the sample KOR. C: chlorite; G: goethite; I: illite; K: kaolinite; Q: quartz; R: rutile; S: smectite. 


\subsection{Effect of Contact Time}

The results obtained during the tests related to kinetics, are presented in Figure 5(a) and Figure 5(b).

Figure 5(a) and Figure 5(b) show that the amount of phosphates adsorbed increases with increasing contact time following two different slopes. The first slope, which is strong, is located in the first 60 minutes of contact and would correspond to a fast adsorption rate. The second slope is gentle and a saturation level is observed. This phase could reflect a slow adsorption rate and express the equilibrium between the adsorption and desorption of phosphates. The major part of the phosphates fixed on the adsorbent, is obtained in the first hour with efficiency in the order of $76 \%, 66 \%, 65 \%$ and $64 \%$ respectively for the samples KOR-Mg, KOR-Na, ANY-Na and ANY-Mg. For the KAT-Mg and KAT-Na

Table 1. Proportion of mineral phases in the clay samples.

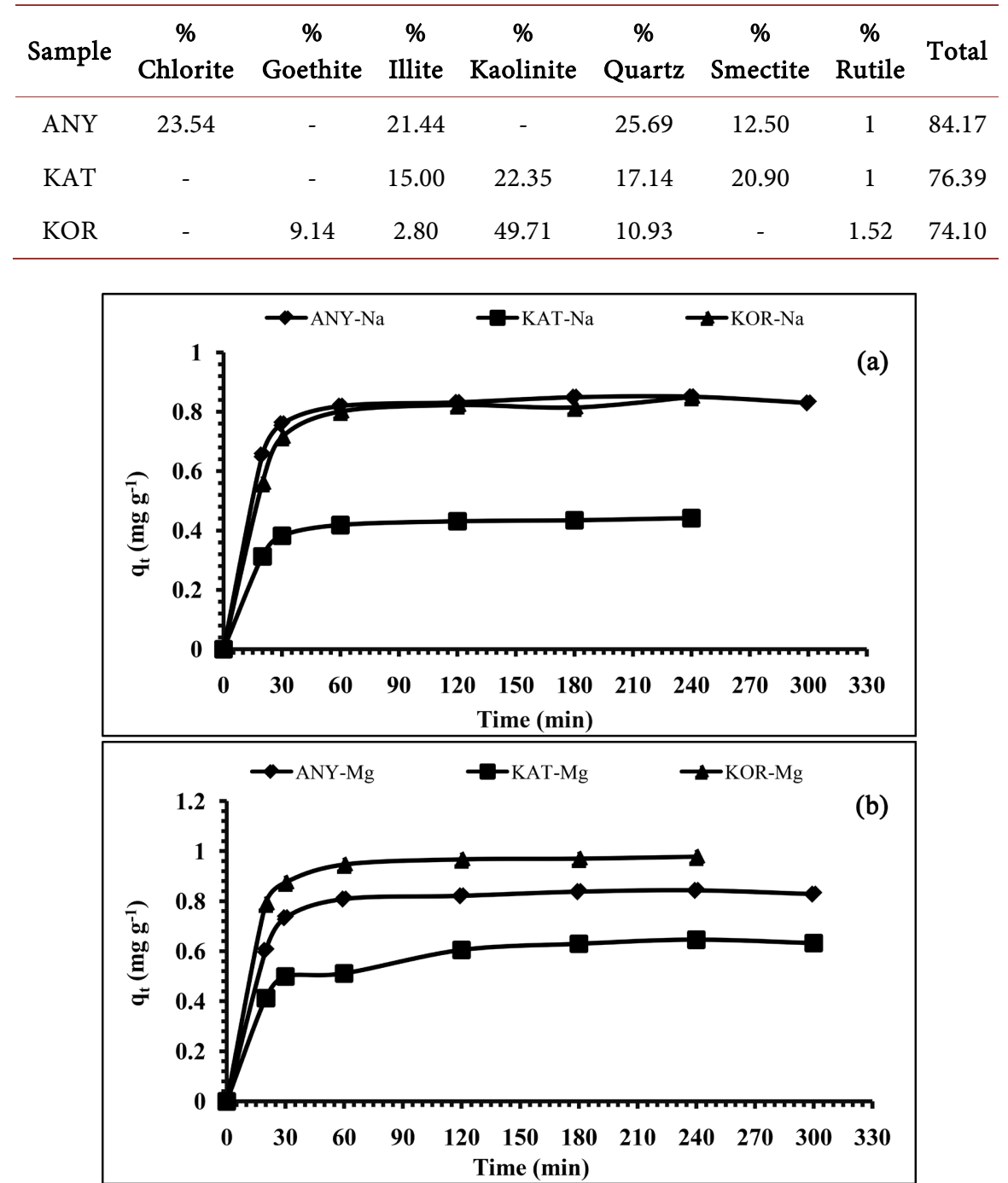

Figure 5. Effect of contact time on the amount of phosphate adsorbed $\left(\mathrm{C}_{0}=5 \mathrm{mg} \cdot \mathrm{l}^{-1}\right.$; clay mass $=40 \mathrm{mg}$; Stirring $=480 \mathrm{rpm} ; \mathrm{V}=10 \mathrm{ml} ; \mathrm{pH}=6.6 ; \mathrm{T}=303 \mathrm{~K}$ ). (a) Sodium samples; (b) Magnesium samples. 
samples, the efficiency were $41 \%$ and $33.5 \%$ respectively.

\subsection{Effect of Clay Mass}

Figure 6(a) and Figure 6(b) show the adsorption efficiency as a function of clay mass.

The results show that the phosphate removal efficiency increases with increasing clay mass. For all the samples except KOR-Mg, a maximum removal of $86.37 \%$ to $97.91 \%$ was obtained for a mass of $40 \mathrm{mg}$ of clay. For KOR-Mg, it is 20 $\mathrm{mg}$. Above $40 \mathrm{mg}$, the removal efficiency is almost constant. This could indicate a saturation of the medium.

\subsection{Effect of $\mathrm{pH}$ on Phosphate Removal}

The results obtained during the tests relating to the influence of the $\mathrm{pH}$ of the medium on the adsorption of phosphates, are presented on Figure 7(a) and Figure 7(b).
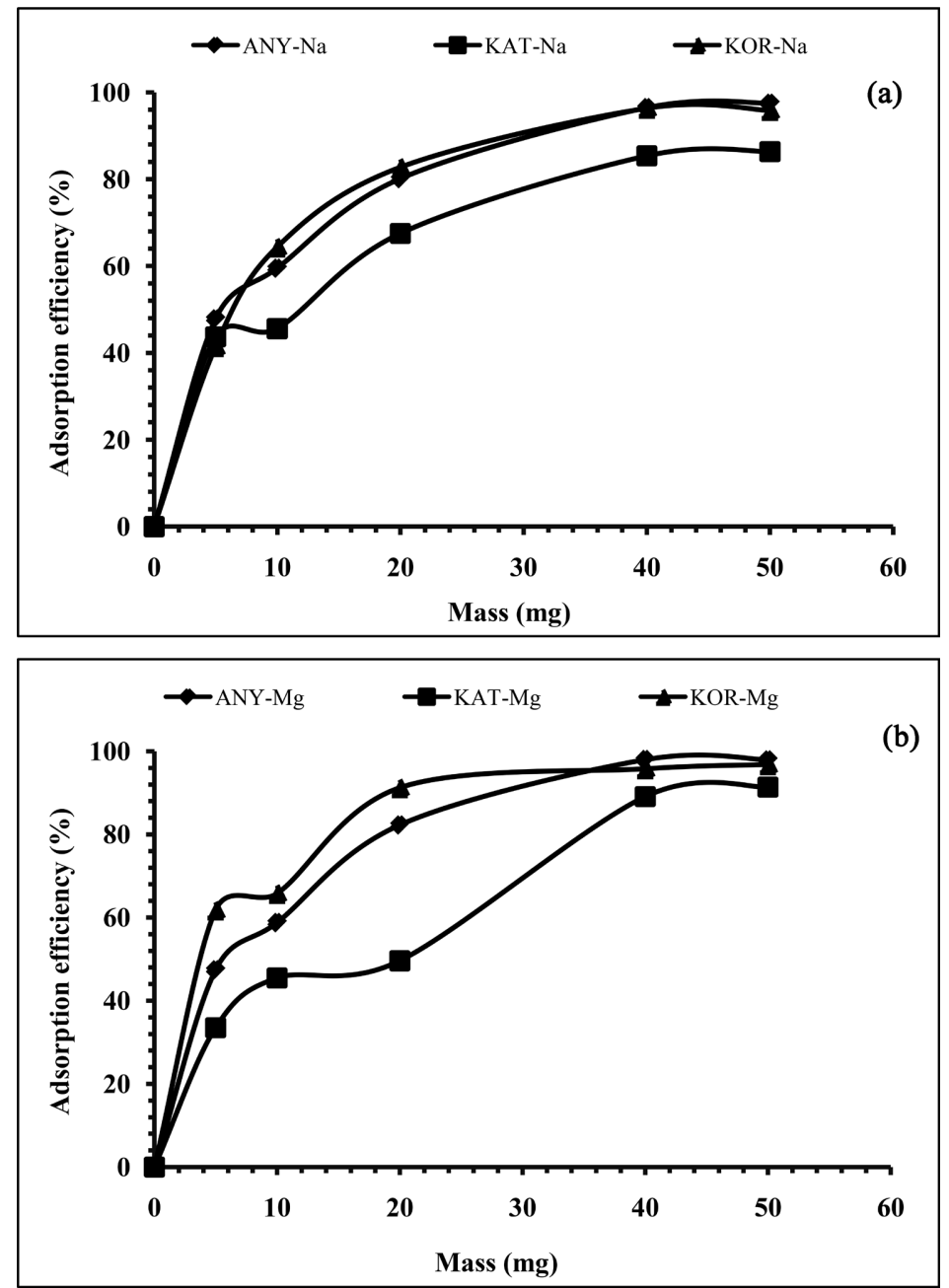

Figure 6. Adsorption efficiency as a function of clay mass $\left(\mathrm{C}_{0}=5 \mathrm{mg} \cdot \mathrm{l}^{-1} ; \mathrm{pH}=6.6\right.$; Stirring $=480 \mathrm{rpm} ; \mathrm{V}=10 \mathrm{ml}$; Contact time $=2 \mathrm{~h} ; \mathrm{T}=303 \mathrm{~K}$ ). (a) Sodium samples; (b) Magnesium samples. 
The results show that the quantity of phosphate adsorbed by the samples increases between $\mathrm{pH}=2$ and $\mathrm{pH}=6$ then a strong decrease is observed when the $\mathrm{pH}$ is higher than 8 . This decrease is probably due to the charged surface of the clay losing the electrostatic attraction on the phosphates. Moreover, the evolution profile of the quantity of phosphates adsorbed from the samples ANY-Na, ANY-Mg, KAT-Mg and KOR-Mg, shows a plateau between $\mathrm{pH} 4$ and $\mathrm{pH}$ 8. For samples KAT-Na and KOR-Na, the evolution profile shows a peak around $\mathrm{pH}$ 6. Overall, the adsorption capacity reaches a maximum value between $\mathrm{pH} 4$ and 8.

\subsection{Effect of Ion Force on Adsorption}

The study of the effect of the salinity of the medium on the adsorption, is represented on Figure 8(a) and Figure 8(b).
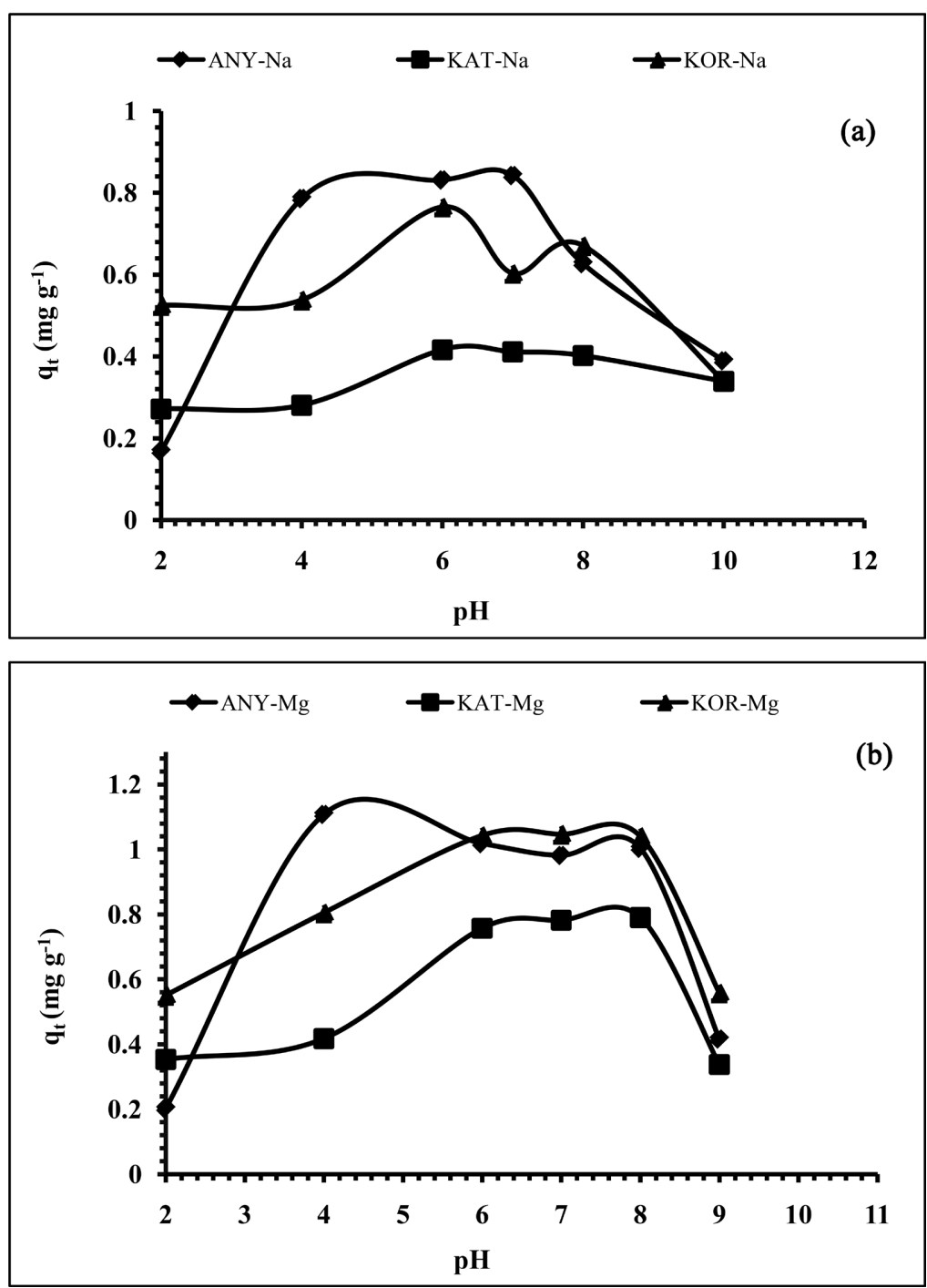

Figure 7. Effect of medium $\mathrm{pH}$ on the amount of phosphate adsorbed $\left(\mathrm{C}_{0}=5 \mathrm{mg} \cdot \mathrm{l}^{-1}\right.$; clay mass $=40 \mathrm{mg}$; Stirring $=480 \mathrm{rpm} ; \mathrm{V}=10 \mathrm{ml}$; Contact time $=2 \mathrm{~h} ; \mathrm{T}=303 \mathrm{~K}$ ). (a) Sodium samples; (b) Magnesium samples. 

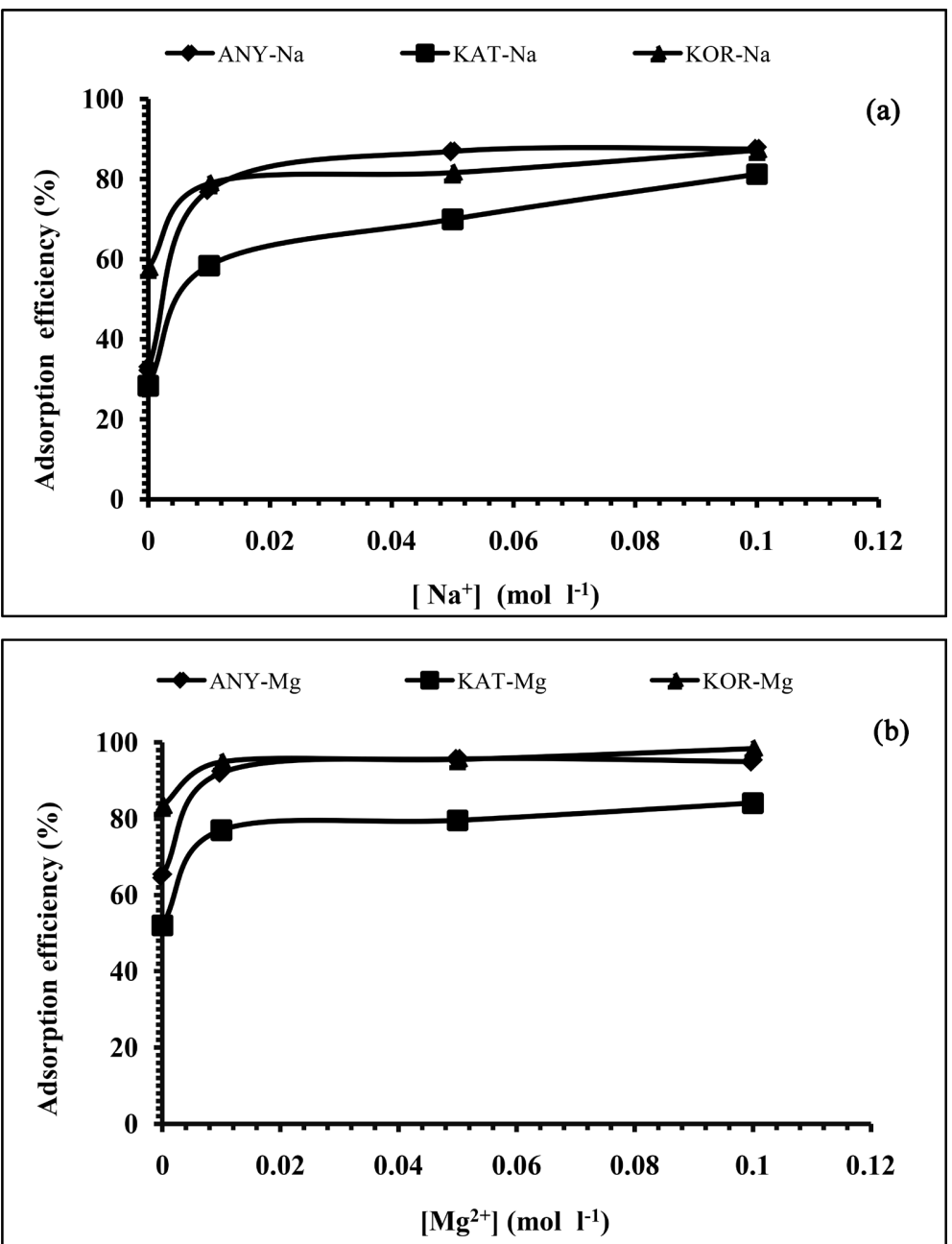

Figure 8. Effect of ion force on the adsorption efficiency $\left(\mathrm{C}_{0}=5 \mathrm{mg} \cdot \mathrm{l}^{-1}\right.$; clay mass $=40$ $\mathrm{mg}$; stirring $=480 \mathrm{rpm} ; \mathrm{V}=10 \mathrm{ml} ; \mathrm{pH}=6.6 ; \mathrm{T}=303 \mathrm{~K}$ ). (a) Sodium samples; (b) Magnesium samples.

The different curves obtained (Figure 8(a) and Figure 8(b)) show two phases. In the first phase, between 0 and $10^{-2} \mathrm{~mol} \cdot \mathrm{l}^{-1}$, the retention rate of phosphates increases rapidly to reach a maximum value at $10^{-2} \mathrm{~mol} \cdot \mathrm{l}^{-1}$. In the second phase (salt content $>10^{-2} \mathrm{~mol} \cdot \mathrm{l}^{-1}$ ), a plateau is observed for samples ANY-Na, ANYMg, KAT-Mg, KOR-Na and KOR-Mg. In contrast, the profile of the sodium KAT sample shows a gentle slope, so that salt addition causes a small change in phosphate removal rate of about $10 \%$. This suggests that ion force has virtually no influence on the process.

\subsection{Effect of Temperature}

The tests relating to the influence of the temperature on the adsorption of phosphates by the clay, gave the results represented on Figure 9(a) and Figure 9(b).

These results reveal that increasing the temperature increases the adsorption capacity of the clay. This suggests that the adsorption reaction is endothermic. 

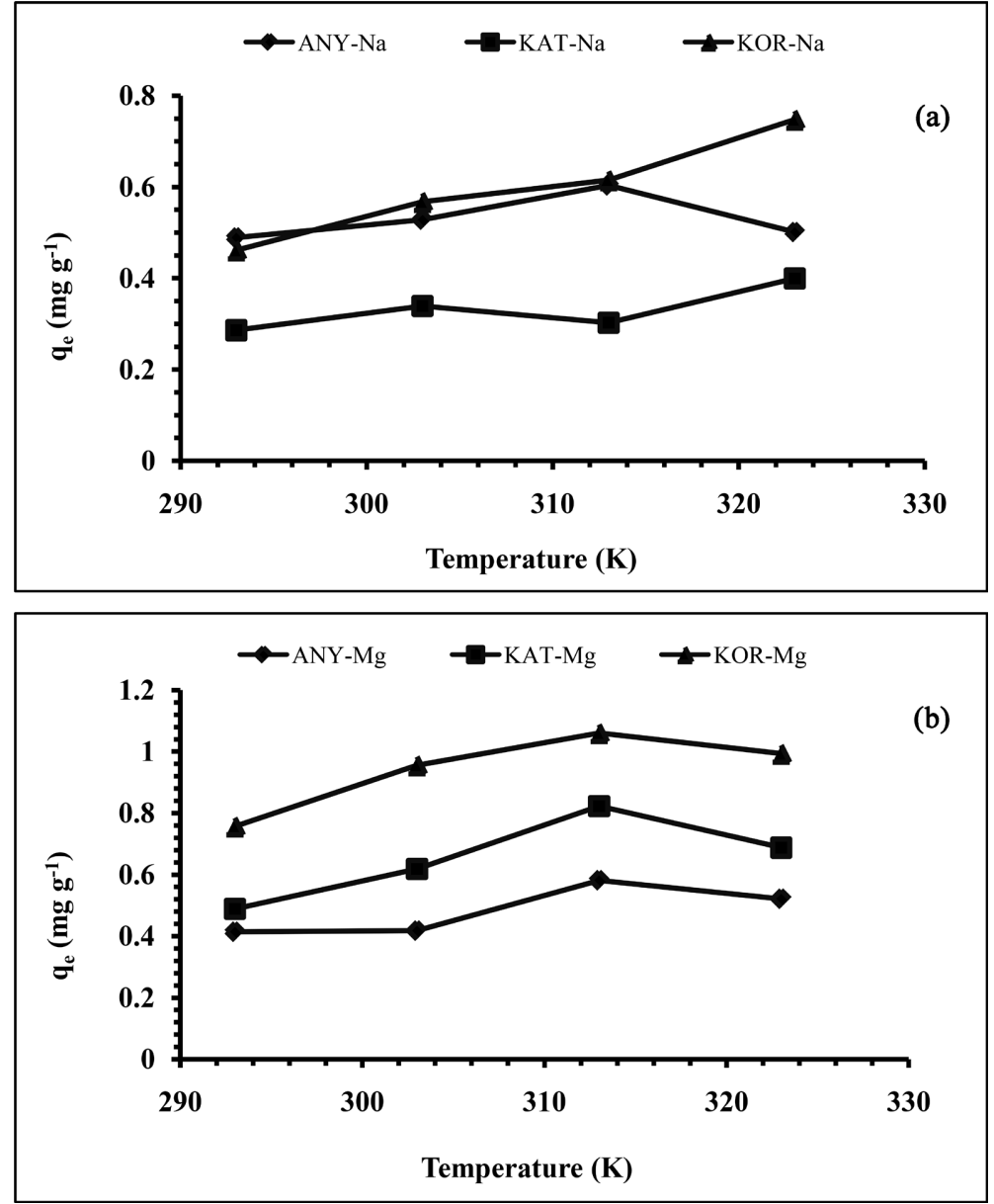

Figure 9. Effect of temperature on the amount of phosphate adsorbed $\left(\mathrm{C}_{0}=5 \mathrm{mg} \cdot \mathrm{l}^{-1}\right.$; clay mass $=40 \mathrm{mg}$; Stirring $=480 \mathrm{rpm} ; \mathrm{V}=10 \mathrm{ml} ; \mathrm{pH}=6.6$ ). (a) Sodium samples; (b) Magnesium samples.

Above $313 \mathrm{~K}$, the adsorption capacity decreases slightly for the samples ANY-Na, ANY-Mg, KAT-Mg and KOR-Mg. This decrease is due to the desorption phenomenon that occurs.

\subsection{Kinetic Models of Adsorption}

The kinetic study of adsorption allows us to examine the influence of contact time on retention. For this purpose, the pseudo first order (Equation (1)) and pseudo second order (Equation (2)) kinetic models were applied to describe the mechanism of phosphate adsorption kinetics by clay samples. Their linear expressions are [15] [16]:

$$
\begin{gathered}
\log \left(q_{e}-q_{t}\right)=\log \left(q_{e}\right)-\frac{k_{1}}{2.303} t \\
\frac{t}{q_{t}}=\frac{1}{k_{2} q_{e}^{2}}+\frac{t}{q_{e}}
\end{gathered}
$$

The parameters of the two kinetic models are grouped in Table 2.

According to the parameters reported in Table 2, in the case of the pseudo-first 
order kinetic model, the experimentally determined amount of phosphates adsorbed at equilibrium is different from the theoretical value. On the other hand, for the pseudo-second order kinetic model, the amount of phosphates adsorbed at equilibrium, determined experimentally is approximately equal to the theoretical value. Moreover, the correlation coefficients $\mathrm{R}^{2}$, are very close to unity for the second order. These last two observations, suggest that the pseudo-second order kinetic model gives a better correlation with the experimental results. On the other hand, magnesium-saturated samples adsorb phosphates more than sodium-saturated samples. The KOR sample has a greater adsorption capacity than the ANY sample which is greater than the KAT sample.

\subsection{Thermodynamic Study of the Adsorption}

The thermodynamic parameters are determined from the following equations [17] [18]:

$$
\begin{gathered}
\ln K_{d}=-\frac{\Delta H}{R T}+\frac{\Delta S}{R} \\
\Delta G=\Delta H-T \Delta S
\end{gathered}
$$

The values of the thermodynamic parameters of the different clay supports used are grouped in Table 3.

Table 2. Kinetic parameters relating to the adsorption of phosphates.

\begin{tabular}{cccccccc}
\hline & \multicolumn{4}{c}{ Pseudo first order } & \multicolumn{3}{c}{ Pseudo second order } \\
\hline Parameters & $\begin{array}{c}\mathrm{q}_{\mathrm{e}}\left(\mathrm{mg} \cdot \mathrm{g}^{-1}\right) \\
\text { exp. }\end{array}$ & $\begin{array}{c}\mathrm{q}_{\mathrm{e}}\left(\mathrm{mg} \cdot \mathrm{g}^{-1}\right) \\
\mathrm{cal} .\end{array}$ & $\begin{array}{c}\mathrm{K}_{1} \\
\left(\mathrm{~min}^{-1}\right)\end{array}$ & $\mathbf{R}^{2}$ & $\begin{array}{c}\mathrm{q}_{\mathrm{e}}\left(\mathrm{mg} \cdot \mathrm{g}^{-1}\right) \\
\mathrm{cal} .\end{array}$ & $\begin{array}{c}\mathrm{K}_{2} \\
\left(\mathbf{g} \cdot \mathbf{m g}^{-1} \cdot \mathrm{min}^{-1}\right)\end{array}$ & $\mathbf{R}^{2}$ \\
\hline ANY-Na & 0.851 & 0.160 & 0.012 & 0.483 & 0.851 & 0.355 & 0.999 \\
KAT-Na & 0.442 & 0.177 & 0.021 & 0.838 & 0.454 & 0.331 & 0.999 \\
KOR-Na & 0.850 & 0.329 & 0.016 & 0.696 & 0.871 & 0.143 & 0.999 \\
ANY-Mg & 0.844 & 0.196 & 0.012 & 0.615 & 0.853 & 0.238 & 0.999 \\
KAT-Mg & 0.646 & 0.284 & 0.012 & 0.854 & 0.665 & 0.130 & 0.998 \\
KOR-Mg & 0.978 & 0.321 & 0.023 & 0.830 & 0.996 & 0.243 & 0.999 \\
\hline
\end{tabular}

\begin{tabular}{|c|c|c|c|c|c|c|}
\hline \multirow{2}{*}{ Sample } & \multicolumn{4}{|c|}{$\Delta \mathrm{G}\left(\mathrm{kJ} \cdot \mathrm{mol}^{-1}\right)$} & \multirow{2}{*}{$\begin{array}{c}\Delta \mathrm{H} \\
\left(\mathrm{kJ} \cdot \mathrm{mol}^{-1}\right)\end{array}$} & \multirow{2}{*}{$\begin{array}{c}\Delta S \\
\left(\mathrm{~J} \cdot \mathrm{mol}^{-1} \cdot \mathrm{K}^{-1}\right)\end{array}$} \\
\hline & $293 \mathrm{~K}$ & $303 \mathrm{~K}$ & $313 \mathrm{~K}$ & $323 \mathrm{~K}$ & & \\
\hline ANY-Na & -12.543 & -13.086 & -13.63 & -14.174 & 3.389 & 54.374 \\
\hline ANY-Mg & -11.662 & -12.521 & -13.38 & -14.238 & 13.502 & 85.884 \\
\hline KAT2-Na & -10.497 & -11.18 & -11.863 & -12.546 & 9.519 & 68.316 \\
\hline KAT2-Mg & -12.64 & -13.812 & -14.984 & -16.157 & 21.708 & 117.227 \\
\hline KOR-Na & -12.105 & -13.317 & -14.529 & -15.741 & 23.412 & 121.218 \\
\hline KOR-Mg & -14.991 & -16.439 & -17.887 & -19.335 & 27.445 & 144.83 \\
\hline
\end{tabular}

Table 3. Values of the thermodynamic parameters. 
The free enthalpy values $\Delta \mathrm{H}$ are positive and less than $40 \mathrm{~kJ} \cdot \mathrm{mol}^{-1}$. This confirms the endothermic nature of the adsorption reaction. The $\Delta G$ values are negative and decrease with increasing temperature. In addition, the $\Delta G$ values are greater than $-20 \mathrm{~kJ} \cdot \mathrm{mol}^{-1}$. These observations show that the adsorption reaction is spontaneous and this spontaneity increases with temperature. For all samples, the positive values of the entropy $\Delta S$, suggest an increase in disorder at the solid-liquid interface during adsorption.

\section{Discussion}

The knowledge of the operating conditions at the dephosphation by clays, led us to study the influence of contact time, clay mass, $\mathrm{pH}$ of the medium, ionic strength and temperature on the adsorption. Thus, the phase of rapid increase of the adsorption capacity being situated in the first 60 minutes of contact, shows that the speed of adsorption is fast. This could be explained by the fact that the electrostatic attraction of the adsorbent surface on the phosphates is accompanied by a great mobility of the ions in solution, which would increase the kinetic energy of these particles, as well as the frequency of collision between them and the surface of the clay. The clay samples used therefore have a high reactivity towards phosphorus. After this phase, the speed becomes slower and slower since the binding forces involved are weak, some adsorbates could detach from the surface (desorption phenomenon) and go into solution. This could lead to an equilibrium between adsorbed and desorbed fractions [15]. The adsorption process does follow the pseudo-second order kinetic model. These results corroborate several studies that have shown that phosphate adsorption kinetics obey the pseudo-second order [12] [13] [14] [19] [20].

Regarding the increase in adsorption efficiency with clay mass, it would be due to the increase in adsorbent surface area and the number of active sites offered on the adsorbent surface [21]. Above $40 \mathrm{mg}$, the removal efficiency is almost constant. This is probably related to the formation of a deposit by aggregate formation in the reactor. Indeed, the increasing contribution in adsorbent leads progressively to the formation of a compact mass of clay. This mass would cause a covering of the contact surfaces, which would make less available the acceptor sites on the surface of the adsorbent and would lead to a saturation of the aqueous medium. Work related to the contact of phosphates with various materials has yielded similar results [12] [22] [23] [24] [25].

In an acidic environment, the adsorption of hydronium ions $\mathrm{H}_{3} \mathrm{O}^{+}$creates additional positive charges on the clay surface, which could increase the electrostatic attraction of phosphate anions. The distribution curve in Figure 10 shows that the phosphate anions are progressively put into solution from $\mathrm{pH} 2$. Thus, the phosphates bind to the charged surface of the clay as they are produced, resulting in an increase in the retention efficiency of the phosphates. A similar result was obtained by [12] [24] [26]. As for the reduction of the performance of retention of phosphorus when the $\mathrm{pH}$ is basic, would be related to several factors. 


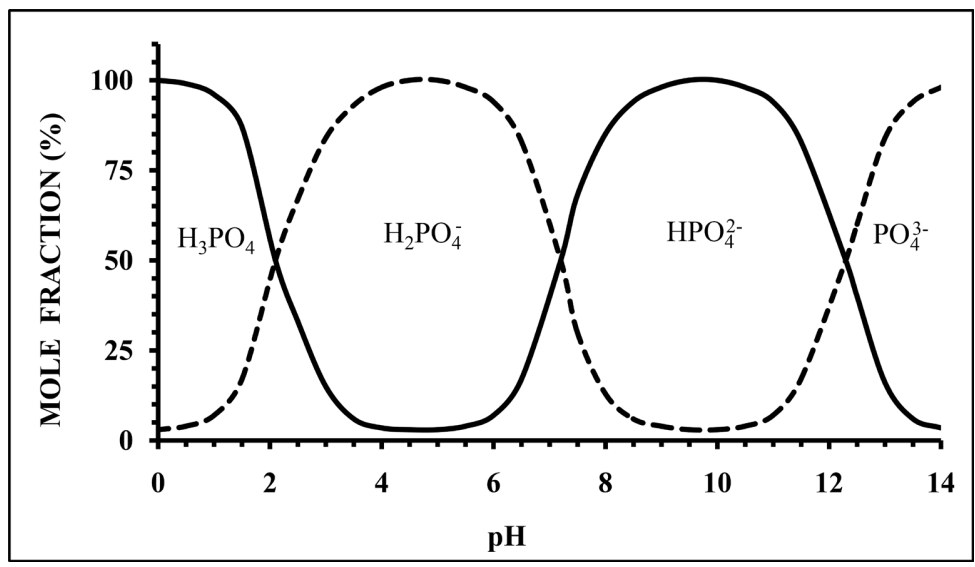

Figure 10. Distribution curves of species from orthophosphoric acid $\mathrm{H}_{3} \mathrm{PO}_{4}$ [31].

It seems that hydroxide ions $\mathrm{OH}^{-}$compete with phosphate ions to occupy the adsorption sites on the one hand, and on the other hand, to the charged surface of the clay which loses the electrostatic attraction on the phosphate anions $\mathrm{HPO}_{4}^{2-}$ and $\mathrm{PO}_{4}^{3-}$ arriving at the adsorbent surface [21]. In a basic environment, negative charges on the clay surface outnumber positive charges. Therefore, the $\mathrm{pH}$ of the medium has an effect on phosphate adsorption. However, the rate of phosphate adsorption is better around a neutral $\mathrm{pH}$. This result corroborates those of [27] [28] [29] [30]. According to [27], the natural environment of $\mathrm{pH}$ varying between 5.5 and 7.5 is favorable for phosphate removal.

The study of the effect of temperature on adsorption showed that the reaction is endothermic in nature. This result is in agreement with those of [27] [32] [33]. Above $313 \mathrm{~K}$, a decrease of the adsorption capacity was observed for some samples. This decrease could be due to the desorption of some phosphates. A similar result was obtained by [23] [24] during nitrate and phosphate removal by a modified bentonite. In Effect, a decrease in adsorption capacity was observed at temperatures above $303 K$ by [23] and $311 K$ by [24] respectively. The magnitude of the free energy $\Delta G$ is used to determine the type of adsorption process [13]. Thus, $\Delta G$ values greater than $-20 \mathrm{~kJ} \cdot \mathrm{mol}^{-1}$, as in our case, would correspond to an electrostatic interaction between the adsorption sites and the phosphate ions. This result explains well the observations of the influence of $\mathrm{pH}$ on adsorption. The values of $\Delta \mathrm{H}$, which are lower than $40 \mathrm{~kJ} \cdot \mathrm{mol}^{-1}$, suggest that the adsorption is due to physisorption or physical adsorption and involves only relatively weak intermolecular forces such as Van Der Waals forces. However, this type of mechanism is characterized by its rapidity and reversibility by allowing an accumulation of layers (multilayer formation). Hence the rapid adsorption kinetics during the first hour of contact and the desorption observed beyond 313 $\mathrm{K}$. Moreover, the increase in temperature could make the bonds involved in the process even weaker, which could lead to the detachment of the adsorbate from the surface and pass into solution.

The phase of increase of the dephosphation rates when the salt concentration is lower than $10^{-2} \mathrm{~mol} \cdot \mathrm{l}^{-1}$, shows that the presence of alkaline elements in solu- 
tion, increases the performance of the adsorbents used. Indeed, the fixation of these alkalis on the surface of the clay could increase the quantity of positive charges and increase the electrostatic attraction of the adsorbent surface on the phosphate anions. Alkalis not retained by the clay, could form screens that would prevent some phosphates from accessing the adsorbent surface so that further adsorption of phosphates would be less easy. This could explain the nearly constant rates when the salt concentration is greater than $10^{-2} \mathrm{~mol} / \mathrm{L}$. However, the presence of $\mathrm{Ca}^{2+}, \mathrm{Mg}^{2+}$, etc. does not interfere with the adsorption process [34]. The performance of magnesian samples must be due to the binding intensity of cations mediating the binding of phosphate ions. This intensity depends on the valence and the degree of hydration of the cation [35]. In fact, weakly hydrated bivalent ions such as $\mathrm{Mg}^{2+}$, i.e. surrounded by a weak layer of water, are more energetically retained than strongly hydrated monovalent ions such as $\mathrm{Na}^{+}$[35]. Thus during saturation of clay samples, the amount of magnesium bound would be large compared to that of sodium. Therefore, magnesium bridges would be more numerous than sodium bridges. Moreover, according to Figure 10, the monovalent phosphoric ion $\mathrm{H}_{2} \mathrm{PO}_{4}^{-}$would be the predominant species in the $\mathrm{pH}$ range of our tests ( $\mathrm{pH}$ between 6 and 7). Thus during the adsorption process, two $\mathrm{H}_{2} \mathrm{PO}_{4}^{-}$ions could be retained via a $\mathrm{Mg}^{2+}$ ion, while via a $\mathrm{Na}^{+}$ion, only one $\mathrm{H}_{2} \mathrm{PO}_{4}^{-}$ion could bind. As a result, magnesian samples could remove more phosphates than sodium samples.

The Korhogo clay had the highest phosphate retention efficiency, followed by the Anyama clay and then the Katiola clay, suggesting that phosphate removal depends on the clay. Indeed, the Korhogo sample, which is mostly kaolinite (49.7\%), contains a significant amount of goethite (9.14\%). This iron oxide strongly increases the specific surface and improves the adsorption capacity [36], since $\mathrm{Fe}^{3+}$ ions have a high affinity for phosphorus. Hence a high adsorption capacity for the KOR sample compared to the others without goethite. Concerning the ANY sample, it contains appreciable quantities of 2:1 minerals such as smectites (12.5\%), illite $(21.44 \%)$ and chlorite (23.54\%), that is to say a total of $57.48 \%$ of $2: 1$ minerals compared to $35.9 \%$ for the KAT sample (20.9\% smectite and $15 \%$ illite) which also contains $22.5 \%$ kaolinite (type 1:1 clay). The ANY sample, which contains more 2:1 minerals, adsorbs phosphates better than the KAT sample. This finding suggests that the mineralogical composition of the clay samples may give an explanation for the different adsorption capacities [37] and then that 2:1 type minerals have greater adsorption capacities compared to 1:1 type minerals [38].

\section{Conclusions}

This study investigated the capacity of the clays to adsorb phosphate ions from aqueous solutions in order to valorize clay materials from Côte d'Ivoire. These clay samples, collected in various regions of Côte d'Ivoire, were characterized by X-ray diffraction. This characterization revealed that the ANY sample contains chlorite, smectites, illite, quartz and rutile; the KAT sample consists of kaolinite, 
smectites, illite, quartz and rutile. KOR Sample contains kaolinite, illite, quartz, rutile and goethite. The study of the factors likely to influence the adsorption, were carried out. The results of the kinetic showed that the adsorption process follows the model of pseudo-second order. The values of the thermodynamic parameters indicate that the reaction is a spontaneous, endothermic physisorption (or physical adsorption) and that a disorder occurs at the solid-liquid interface during the reaction. The adsorption of phosphates is influenced by the $\mathrm{pH}$ of the medium, the temperature, the valence of the saturating cation and its degree of hydration, the presence of iron oxide and the mineralogical composition of the clay. However, the salinity of the medium does not disturb the process.

In perspective, it would be pertinent:

- to treat the natural effluents with the clay materials. Indeed, the natural water has a much more complex composition than the synthetic solutions which were used for this work. Thus a comparison could be made on the thermodynamic and kinetic plan and to check if there is similarity of the results;

- to study the desorption of phosphates retained on the surface of the clay in order to consider a probable use of the sludge produced as fertilizer in agriculture since some samples showed a tendency to desorption.

\section{Conflicts of Interest}

The authors declare no conflicts of interest regarding the publication of this paper.

\section{References}

[1] Beaudin, I., Beaudet, P., Giroux, M., Mailloux, A., Martin, Y., Michaud, A., Pellerin, A., Rivest, R. and Eric, V.B. (2006) Literature Review-Phosphorus Mobility, Final Version. Centre de Référence en Agriculture et Agroalimentaire du Québec (CRAAQ).

[2] Devidal, S., Rivard-Sirois, C., Pouet, M.F. and Thomas, O. (2007) Healing Solution for the Restoration of Lakes Showing Signs of Eutrophisation, Internal Report. Observatory of the Environment and Sustainable Developenment. University of Sherbrooke, Québec, 51 p.

[3] Morteau, B., Galvez-Cloutier, R. and Leroueil, S. (2006) Development of a Treatment Chain for the Mitigation of Contaminants from Maintenance Products on the FélixLeclerc Highway: Filter Bed and Adapted Purifying Wetland. Ministère des Transport de Québec, 45 p.

[4] Yang, X.E., Wu, X., Hao, H.L. and He, Z.L. (2008) Mechanisms and Assessment of Water Eutrophication. Journal of Zhejiang University SCIENCE B, 9, 197-209. https://doi.org/10.1631/jzus.B0710626

[5] Daouda, M. (2010) Methodology and Results of the Diagnosis of Eutrophication of Lake Nokoue (Benin). Ph.D. Thesis, University of Limoges, Limoges, 158 p.

[6] Dubus, I. (1997) Phosphorus Retention in Soils: Study Principle, Modeling, Mechanisms and soil Compartments Involved. ORSTOM Nouméa, Documents Scientifiques et Techniques, 3, 76.

[7] Behmel, S. (2015) Memorandum on the Implementation of Curative Measures to Combat Eutrophication in Lake Saint-Charles. Technical Report, Laval University, Laval, 15 p. 
[8] Hill, P.M. and Coetzee, J.A. (2008) Integrated Control of Water Hyacinth in Africa. EPPO Bulletin, 38, 452-457. https://doi.org/10.1111/j.1365-2338.2008.01263.x

[9] Bouaoun, D. and Aoun, J. (2004) Removal of Phosphorus, Ammonium and Nitrates by Phase Alternation in Biological Reactors. Francophone Journal of Industrial Ecology, $\mathrm{N}^{\circ} 35,28-32$.

[10] Cabanes, F. (2006) Dephosphatation of Effluents: Precipitation and Valorization of Phosphorus. Thesis of the Institut National Polytechnique of Toulouse (France), $219 \mathrm{p}$.

[11] Smith, V.H., Tilman, G.D. and Nekola, J.C. (1999) Eutrophication: Impacts of Excess Nutrient Inputs on Fresh Water, Marine and Terrestrial Ecosystems. Environmental Pollution, 100, 179-196. https://doi.org/10.1016/S0269-7491(99)00091-3

[12] Coulibaly, S.L. (2014) Abatement of Phosphates from Wastewater by Adsorption on Geomaterials Consisting of Laterite, Sandstone and Slate Shale. Ph.D. Thesis, University of Lorraine and the Université Nangui Abrogoua, 213 p.

[13] Leduc, J.F., Leduc, R. and Cabana, H. (2014) Phosphate Adsorption on ChitosanBased Hydrogel Microspheres. Adsorption Science and Technology, 32, 557-569. https://doi.org/10.1260/0263-6174.32.7.557

[14] Saad, R. (2008) Adsorption and Desorption of Phosphate and Nitrate Ions by SilicaBased Mesoporous Materials Functionalized with Ammonium Groups. Ph.D. Thesis, Laval University, Laval, $156 \mathrm{p}$.

[15] Belaid, K.D. and Kacha, S. (2011) Study of the Kinetics and Thermodynamics of the Adsorption of a Basic Dye on Sawdust. Journal of Water Science, 24, 131-144. https://doi.org/10.7202/1006107ar

[16] Ho, Y.S. and McKay, G. (1999) Pseudo-Second Order Model for Sorption Processes. Process Biochemistry, 34, 451-465. https://doi.org/10.1016/S0032-9592(98)00112-5

[17] Bouberka, Z., Kacha, S., Kameche, M., Elmaleh, S. and Derriche, Z. (2005) Sorption Study of an Acid Dye from Aqueous Solution Using Modified Clays. Journal of Hazardous Materials, 119, 117-124. https://doi.org/10.1016/j.jhazmat.2004.11.026

[18] Gok, C. and Aytas, S. (2009) Biosorption of Uranium (VI) from Aqueous Solution Using Calcium Alginate Beads. Journal of Hazardous Materials, 168, 369-375. https://doi.org/10.1016/j.jhazmat.2009.02.063

[19] Ho, Y.S., NgI, Y. and McKay, G. (2000) Kinetics of Pollutant Sorption by Biosorbents: Review. Separation and Purification Methods, 29, 189-232. https://doi.org/10.1081/SPM-100100009

[20] Rudzinski, W. and Plazinski, W. (2006) Kinetics of Solute Adsorption at Solid/Solution Interfaces: A Theoretical Development of the Empirical Pseudo-First and Pseudo Second Order Kinetic Rate Equations, Based on Applying the Statistical Rate Theory of Interfacial Transport. The Journal of Physical Chemistry B, 110, 16514-16525. https://doi.org/10.1021/jp061779n

[21] Karaca, S., Gurses, A., Ejder, M. and Acikyildiz, M. (2006) Adsorptive Removal of Phosphate from Aqueous Solutions Using Raw and Calcinated Dolomite. Journal of Hazardous Materials, 128, 273-279. https://doi.org/10.1016/j.jhazmat.2005.08.003

[22] Babatunde, A.O., Zhao, Y.Q., Burke, A.M., Morris, M.A. and Hanrahan, J.P. (2009) Characterization of Aluminum-Based Water Treatment Residual for Potential Phosphorus Removal in Engineered Wetlands. Environment Pollution, 157, 2830-2836. https://doi.org/10.1016/j.envpol.2009.04.016

[23] Gezahegn, F., Wasse, B. and Nestor, F. (2014) Removal of Nitrate Ion from Aqueous Solution by Modified Ethiopian Bentonite Clay. International Journal of Research 
in Pharmacy and Chemistry (IJRPC), 4, 192-201.

[24] Tang, Y., Tong, Z., Wei, G., Li, Z. and Liang, D. (2006) Removal of Phosphate from Aqueous Solution with Modified Bentonite. The Chinese Journal of Process Engineering, 6, 197-200.

[25] Yoon, S.Y., Lee, C.G., Park, J.A., Kim, J.H. and Kim, S.B. (2014) Kinetic, Equilibrium and Thermodynamic Studies for Phosphate Adsorption to Magnetic Iron Oxide Nanoparticles. Chemical Engineering Journal, 236, 341-347. https://doi.org/10.1016/j.cej.2013.09.053

[26] Sei, J. (1998) Study of Materials of Reduced Dimensionality. Relation StructuresProperties in Natural Kaolinites of Ivory Coast. Doctoral Thesis of the University of Montpellier II, $252 \mathrm{p}$.

[27] Benzizoune, S., Nassali, H. and Srhiri, A. (2004) Study of the Adsorption Kinetics of Phosphorus in Solution on the Sediments of Fouarat Lake in Morocco. Larhyss Journal, $\mathrm{N}^{\circ} 3,171-184$.

[28] Chitrakar, R., Tezuka, S., Sonoda, A., Sakane, K., Ooi, K. and Hirotsu, T. (2006) Phosphate Adsorption on Synthetic Goethite and Akaganeite. Journal of Colloid and Interface Science, 298, 602-608. https://doi.org/10.1016/j.jcis.2005.12.054

[29] Kuzawa, K., Jung, Y., Kiso, Y., Yamada, T., Nagai, M. and Lee, T. (2006) Phosphate Removal and Recovery with a Synthetic Hydrotalcites as an Adsorbent. Chemosphere, 62, 45-52. https://doi.org/10.1016/j.chemosphere.2005.04.015

[30] Ookubo, A., Ooi, K. and Hayashi, H. (1993) Preparation and Phosphate Ion-Exchange Properties of a Hydrotalcite-Like Compound. Langmuir, 9, 1418-1422. https://doi.org/10.1021/la00029a042

[31] Boyd, C.E. (1982) Water Quality Management for Pond Fish Culture. Elsevier Scientific Publishing Company, Singapore, 318 p.

[32] Mehmed, E.A., Sukru, D., Celalettin, O. and Mustafa, K. (2007) Heavy Metal Adsorption by Modified Oak Sawdust: Thermodynamics and Kinetics. Journal of Hazardous Materials, 141, 77-85. https://doi.org/10.1016/j.jhazmat.2006.06.095

[33] Zeng, L., Li, X. and Liu, J. (2004) Adsorptive Removal of Phosphate from Aqueous Solutions Using Iron Oxide Tailings. Water Research, 38, 1318-1326.

https://doi.org/10.1016/j.watres.2003.12.009

[34] Saad, R., Belkaeemi, K. and Hamoudi, S. (2007) Adsorption of Phosphate and Nitrate Anions on Ammonium-Functionalized MCM-48: Effects of Experimental Conditions. Journal of Colloid and Interface Science, 311, 375-381. https://doi.org/10.1016/j.jcis.2007.03.025

[35] Soltner, D. (1992) Les bases de la production végétale Tome 1: Le sol et son amélioration. 19th Edition, Sciences et Techniques Agricoles, Sainte Gemmes sur Loire.

[36] Sei, J., Jumas, J.C., Olivier-Fourcade, J., Quiquampoix, H. and Staunton, S. (2002) Role of Iron Oxides in the Phosphate Adsorption Properties of Kaolinites from the Ivory Coast. Clays and Clay Minerals, 50, 217-222.

https://doi.org/10.1346/000986002760832810

[37] Kedi, A.B.B., Kouassi, S.S., Coulibaly, V. and Sei, J. (2021) Removal of Pollutants from Liquid Waste of a Sugar Production Unit by Natural Clays from Ivory Coast. International Journal of Biological and Chemical Sciences, 15, 803-815. https://doi.org/10.4314/ijbcs.v15i2.31

[38] Gu, S., Kang, X., Wang, L., Lichtfouse, E. and Wang, C. (2019) Clay Mineral Adsorbents for Heavy Metal Removal from Wastewater: A Review. Environmental Chemistry Letters, 17, 629-654. https://doi.org/10.1007/s10311-018-0813-9 